\title{
The Relationship between Cultural Background and Reading Comprehension
}

\author{
Hedieh Yousef \\ Kermanshah Science and Research Branch, Islamic Azad University, Kermanshah, Iran \\ Lotfollah Karimi \\ English Department, Hamadan Branch, Islamic Azad University, Hamadan, Iran \\ Kamaran Janfeshan \\ English Department, Kermanshah Branch, Islamic Azad University, Kermanshah, Iran
}

\begin{abstract}
This study was an attempt to investigate the relationship between cultural background of Iranian EFL learners and reading comprehension. 45 Iranian language learners majoring in TEFL and English language translation from three different ethnicities in different provinces were selected through purposive sampling. All participants received three different reading comprehension sub-tests: a reading sub-test including culturally familiar topics and two reading sub-tests with culturally unfamiliar topics. The results showed that the means of all groups on culturally familiar reading tests were greater than their means on reading tests with unfamiliar contents.
\end{abstract}

Index Terms - cultural background, schema, reading comprehension

\section{INTRODUCTION}

Reading comprehension as an important language skill for L1 and L2 readers is greatly influenced by many factors. Among these factors is the role which background knowledge or familiarity with the texts plays in reading comprehension. The question raised in this study was if there was any relationship between cultural background and reading comprehension.

Schema theory emphasizes that reading comprehension is an interactive process between the reader's previous background knowledge and the text. According to the theory, ESL readers' reading comprehension is not only due to how easy or difficult a text is for them but more depends on the level of readers' recall from their culturally familiar background knowledge and from the contextual clues about cultural origins (Carrell, 1984; Carrell, 1987; Floyd \& Carrell, 1987). Generally, there are three major types of schemata, namely, formal schemata, content schemata and cultural schemata, which are closely related to reading comprehension.

Carrell and Eisterhold (1983) have stated that content schema refers to the readers' familiarity with the subject matter of the text. A study carried out by Koh (1986) to show the impacts of familiar context on student's reading comprehension supports the notion that one's comprehension of a text depends on how much relevant prior knowledge the reader has about the subject matter of that particular text. He has also suggested that students must be made conscious of what is involved in successful reading. Alvermann and Readence (1985) have suggested that when prior knowledge which contradicts information in the text is activated, readers may let prior knowledge override the text.

Formal schema, also called textual schema (Singhal, 1998), is defined as knowledge of language and linguistic conventions, including knowledge of how texts are organized and what the main features of a particular genre of writing are (Alderson, 2000; Carrell, 1987, 1988; Carrell \& Eisterhold, 1983). According to Carrell (1987) "research into formal schema suggests that texts with familiar rhetorical organization should be easier to read and comprehend than texts with unfamiliar rhetorical organization" (p. 464).

Content schema, which is described as knowledge of the content (Carrell, 1983), can further be divided into two different types: background knowledge and subject matter knowledge. The former refers to the knowledge that may or may not be relevant to the content of a particular text, and the latter is directly related to the text content and topic (Alderson, 2000).

The relationship between background knowledge and reading comprehension in native language has been investigated extensively. Results in this area have shown a facilitating effect on reading comprehension, in both adults and children, of having background knowledge of the topic of a text (Anderson \&Pearson, 1984; Weber, 1991). Lipson (1983) compared the reading comprehension of children in relation to their religious affiliation and found an effect of religious affiliation on reading comprehension when children read texts about a topic dealing with aspects of their familiar or unfamiliar religion.

Some researchers have also provided evidence for a potential role of background knowledge in reading comprehension in a second/ foreign language. Droop and Verhoeven (1996) have suggested that via reading-aloud 
protocols, retelling, and questioning, the children's reading performance on the distinguished types of texts were analyzed. A facilitating effect of cultural familiarity was found for both reading comprehension and reading efficiency. Bernhardt (2005) findings suggested that texts which contain culturally familiar content schema are easier to process.

A number of studies regarding the activation of content schema suggest some ways to EFL teachers. As Anderson and Pearson (1984) have argued that the readers are able to only fully comprehend a text if they already know quite a bit about what is in the text. Krashen (1993) has suggested two ways to activate the students' schemata. The first, Free Voluntary Reading, is to have the students select and read texts that are of interest to them. His second suggestion is to have them read in their first language so as to build up the knowledge base necessary to understand them in the second language.

\section{METHOD}

\section{A. Design}

The research used in the present study has been ex-post facto with within-subjects design. In this design the existing groups with their own specific cultural background were compared in terms of some dependent variables. That is, different groups' scores on culturally specific section of reading comprehension tests were labeled as dependent variable. The groups were labeled independent variable.

\section{B. Participants}

To homogenize the sample cut from research population (Arabs=35, Kurds=32, Turks=28) a general English test consisting of 30 multiple-choice items in reading comprehension, adopted from Longman paper and pencil sample test (2011), was administered. On the basis of the test results, the population was sorted into two groups of high-level (scores above 20 out of 30) and low-level (scores below 20 out of 30). Out of high-level students, altogether 45 Iranian EFL language learners, 15 Arabs, 15 Turks, and 15 Kurds, with the average age of 22, were purposively selected as the participants of the study. They were all undergraduate students majoring in English Translation and TEFL in Islamic Azad Universities of Kurdistan, Khuzestan (Abadan), and Tabriz, Iran. The criteria for including the participants in the study were 1) belonging to one of the three aforementioned ethnicities (Arab, Kurd, and Turk), 2) having passed the course of reading I, 3) having taken reading course II, and 4) their score in the general English test administered. They were assured that the information about their ethnicities as well as their scores on the test would be kept confidential.

\section{Instruments}

\section{General reading test}

This test was adopted from Longman paper and pencil sample test (2011). It consisted of 30 multiple choice items. The passages were all about general topics. This test served as a placement test to identify whether the participants were initially homogenous or not so that the researchers could generalize any possible differences between the groups to the role of cultural familiarity. The reliability of this test was estimated through KR-21 method and the reliability index was estimated to be 0.76 .

\section{Culture specific tests for groups}

A reading comprehension test consisting of three culture-oriented subtests was used for collecting data. Each subtest consisted of four or five passages containing culturally specific topics such as music, wedding ceremony, way of dressing, behavior, and Nowruz (new year festival).

Based on Flesch-Kincaid Reading Ease, Online Readability Measurement (www.standardsschmandards.com/exhibits/rix/index.php), the readability of each of the three passages (Arabs', Kurds' and Turks' culture specific passages) was measured and turned out to be $0.40,0.48$, and 0.37 respectively. According to the interpretation of this test, indexes ranging from 0.30 to 0.49 indicate the "difficult readability" level which is appropriate for college students. As the readability level of these three passages fall within this range, the reading comprehension passages (as tests) given to the participants have been suitable for their level.

The reliability of each sub-test estimated through KR-21 formula was 0.80 (for Kurdish culture), 0.70 (for Arabic culture), and 0.69 (for Turkish culture) when answered by Kurd participants; when answered by the Turk participants, the gained reliabilities were $0.81,0.75$ and 0.72 , and when answered by the Arab participants, the reliabilities estimated were $0.70,0.85$, and 0.72 .

\section{Procedure}

After selecting the participants based on the 4 criteria mentioned in the "participants" part, the culture oriented test package was administered to the groups in different cities in three separate 30-minute sessions. In each session a part (containing a specific cultural background) of the test package was administered. To remove the effect of the tiredness of the participants there was a 30 minute-break with refreshment after each session.

Ethically, to take care of the psychological security of the participants, they were assured that the results of the test or their scores were not considered as a kind of evaluation concerning their knowledge of language. Moreover, to keep them anonymous, they were asked not to write their names on the question and answer sheets. In these ways the consent of the participants was obtained. 


\section{DATA ANALYSIS}

To analyze the data collected, one-way ANOVA for correlated scores (within-subjects factor/design) or repeated measures (Ary et al., 2006) was used and the results are presented as follows.

TABLE (1):

DESCRIPTIVE STATISTICS FOR ARAB STUDENTS

\begin{tabular}{|l|l|l|l|}
\hline & Mean & Std. Deviation & N \\
\hline Arabic text & 13.3333 & 1.39728 & 15 \\
Turkish text & 8.4667 & 1.30201 & 15 \\
Kurdish text & 8.3333 & 1.44749 & 15 \\
\hline
\end{tabular}

TABLE (2)

MAUCHLY'S TEST OF SPHERICITY FOR ARAB STUDENTS

\begin{tabular}{|l|l|l|l|l|l|l|l|}
\hline $\begin{array}{l}\text { Within Subjects } \\
\text { Effect }\end{array}$ & $\begin{array}{l}\text { Mauchly's } \\
\text { W }\end{array}$ & $\begin{array}{l}\text { Approx. } \\
\text { Chi-Square }\end{array}$ & df & Sig. & & Epsilon & \\
\cline { 7 - 9 } & & & Greenhouse-Geisser & Huynh-Feldt & Lower-bound \\
\hline factor1 & 0.140 & 25.599 & 2 & 0.000 & 0.538 & 0.546 & 0.500 \\
\hline
\end{tabular}

As the results in Table (2) show, the assumption of sphericity was not met $(\mathrm{p}<0.05)$. So, we cannot rely on the multivariate test. The "epsilon" values on the right-hand side of Table (2) are three different ways to calculate an appropriate adjustment to the degrees of freedom of the F test. Table (3) shows the revised results using each of these corrections.

TABLE (3):

TESTS OF WITHIN-SUBJECTS EFFECTS FOR ARAB STUDENTS

\begin{tabular}{|ll|l|l|l|l|l|}
\hline Source & & $\begin{array}{l}\text { Type III Sum of } \\
\text { Squares }\end{array}$ & Df & Mean Square & F \\
\hline \multirow{5}{*}{ factor1 } & Sphericity Assumed & 243.511 & 2 & 121.756 & 74.400 \\
& Greenhouse-Geisser & 243.511 & 1.07 & 226.517 & 74.400 \\
& Huynh-Feldt & 243.511 & 1.09 & 222.817 & 74.400 \\
& Lower-bound & 243.511 & 1.000 & 243.511 & 74.400 \\
& Sphericity Assumed & 45.822 & 28 & 1.637 & 0.000 \\
Error(factor1) & Greenhouse-Geisser & 45.822 & 15.050 & 3.045 & \\
& Huynh-Feldt & 45.822 & 15.300 & 2.995 & \\
& Lower-bound & 45.822 & 14.000 & 3.273 & & \\
\end{tabular}

Mauchly's test indicated that the assumption of sphericity had been violated, $\left\{x^{2}(2)=243.511, \mathrm{p}<0.05\right\}$. Therefore, degrees of freedom were corrected using Greenhouse-Geisser estimates $(\mathrm{e}=.538)$. The results showed that there was a significant effect of the sub-test taken, $[\mathrm{F}(1.07,15.05)=74.4, \mathrm{p}=.000, \mathrm{p}<0.5]$. That is, the participants had different performances on the three different sub-tests. To find the sources of differences, we ran a post hoc test the results of which are presented in Table (4).

TABLE (4):

PAIRWISE COMPARISONS

\begin{tabular}{|c|c|c|c|c|c|c|}
\hline \multirow[b]{2}{*}{ (I) factor 1} & \multirow[b]{2}{*}{ (J) factor 1} & \multirow[b]{2}{*}{ Mean Difference (I-J) } & \multirow[b]{2}{*}{ Std. Error } & \multirow[b]{2}{*}{ Sig. } & \multicolumn{2}{|c|}{$95 \%$ Confidence Interval for Difference } \\
\hline & & & & & Lower Bound & Upper Bound \\
\hline \multirow[t]{2}{*}{ Arabic } & Turkish & $4.133^{*}$ & .435 & 0.000 & 3.200 & 5.066 \\
\hline & Kurdish & $4.400^{*}$ & .349 & 0.000 & 3.651 & 5.149 \\
\hline Turkish & Kurdish & 0.267 & 0.182 & 0.164 & -.123 & 0.656 \\
\hline
\end{tabular}

As the results in Table (4) show, there has been a significant difference between the Arab students' mean on reading test with Arabic background and their means on the other two sub-tests (Turkish and Kurdish), p = 0.000, mean differences $=4.13$ and 4.40. However, the results show that the difference between the Arab students' means on reading passages with Turkish and Kurdish passages was not significant, $p=0.164$, mean difference $=0.267$.

TABLE (5):

DESCRIPTIVE STATISTICS FOR TURK STUDENTS

\begin{tabular}{|l|l|l|l|}
\hline & Mean & Std. Deviation & N \\
\hline Turkish text & 13. & 1.2 & 15 \\
Arabic text & 8.7 & 1.3 & 15 \\
Kurdish text & 8.9 & 1.5 & 15 \\
\hline
\end{tabular}


TABLE (6):

MAUCHLY'S TEST OF SPHERICITY FOR TURK STUDENTS

\begin{tabular}{|l|l|l|l|l|l|l|l|}
\hline $\begin{array}{l}\text { Within Subjects } \\
\text { Effect }\end{array}$ & Mauchly's W & Approx. Chi-Square & Df & Sig. & \multicolumn{2}{|l|}{ Epsilon $^{\text {b }}$} \\
\cline { 6 - 8 } & & & & & Greenhouse-Geisser & Huynh-Feldt & Lower-bound \\
\hline factor1 & 0.15 & 27 & 2 & 0.000 & 0.54 & 0.55 & 0.51 \\
\hline
\end{tabular}

As the results in Table (6) show, the assumption of sphericity was not met $(\mathrm{p}<0.05)$. Table $(7)$ shows revised results using each epsilon values.

TABLE (7):

TESTS OF WITHIN-SUBJECTS EFFECTS FOR TURK STUDENTS

\begin{tabular}{|ll|l|l|l|l|l|}
\hline Source & & Type III Sum of Squares & df & Mean Square & F & Sig. \\
\hline \multirow{5}{*}{ factor1 } & Sphericity Assumed & 243.511 & 2 & 124.756 & 74.7 & 0.000 \\
& Greenhouse-Geisser & 243.511 & 1.12 & 228.517 & 74.7 & 0.000 \\
& Huynh-Feldt & 243.511 & 1.093 & 224.817 & 74.7 & 0.000 \\
& Lower-bound & 243.511 & 1.000 & 249.511 & 74.7 & 0.000 \\
& Sphericity Assumed & 45.822 & 28 & 1.7 & \\
& Greenhouse-Geisser & 45.822 & 15.03 & 3.07 & \\
& Huynh-Feldt & 45.822 & 15.300 & 2.995 & & \\
& Lower-bound & 45.822 & 14.000 & 3.273 & & \\
\end{tabular}

Mauchly's test indicated that the assumption of sphericity was not $\operatorname{met}\left\{x^{2}(2)=27, p<0.05\right\}$. Therefore, degrees of freedom were corrected using Greenhouse-Geisser estimates $(\mathrm{e}=.54)$. The results show that there has been a significant effect of the sub-test taken $\{\mathrm{F}(1.12,15.03)=74.9, \mathrm{p}=.000\}$. The results show that the participants had different performance on the three different tests. In order to find the sources of differences, we ran a post hoc test the results of which are shown Table (8).

TABLE (8):

PAIRWISE COMPARISONS

\begin{tabular}{|c|c|c|c|c|c|c|}
\hline \multirow[b]{2}{*}{ (I) factor 1} & \multirow[b]{2}{*}{$(\mathrm{J})$ factor 1} & \multirow[b]{2}{*}{ Mean Difference (I-J) } & \multirow[b]{2}{*}{ Std. Error } & \multirow[b]{2}{*}{ Sig. } & \multicolumn{2}{|c|}{$95 \%$ Confidence Interval for Difference } \\
\hline & & & & & Lower Bound & Upper Bound \\
\hline \multirow[t]{2}{*}{ Kurdish } & Arabic & 4.3 & 0.435 & 0.000 & 3.3 & 5.07 \\
\hline & Turkish & 4.1 & 0.349 & 0.000 & 3.7 & 5.2 \\
\hline Arabic & Kurdish & 0.2 & 0.182 & 0.17 & -.14 & 0.66 \\
\hline
\end{tabular}

As the results in Table (8) show, there has been a significant difference between the Turk students' mean on reading test with Turkish background and their means on the other two tests( Arabic and Kurdish), $\mathrm{p}=0.000$, mean differences= 4.3 and 4.1. However, the results show that the difference between the Turk students' means on reading passages with Arabic and Kurdish passages has not been significant, $\mathrm{p}=0.17$ and mean difference is 0.2 .

TABLE (9):

DESCRIPTIVE STATISTICS FOR KURD STUDENTS

\begin{tabular}{|l|l|l|l|}
\hline & Mean & Std. Deviation & N \\
\hline Kurdish text & 12.9 & 1.23 & 15 \\
Arabic text & 8.8 & 1.4 & 15 \\
Turkish text & 8.7 & 1.6 & 15 \\
\hline
\end{tabular}

TABLE (10):

MAUCHLY'S TEST OF SPHERICITY FOR KURDISH STUDENTS

\begin{tabular}{|l|l|l|l|l|l|l|l|}
\hline $\begin{array}{l}\text { Within Subjects } \\
\text { Effect }\end{array}$ & Mauchly's W & $\begin{array}{l}\text { Approx. Chi- } \\
\text { Square }\end{array}$ & Df & Sig. & Epsilon & \multicolumn{2}{l|}{} \\
\cline { 6 - 9 } & & & & Greenhouse-Geisser & Huynh-Feldt & Lower-bound \\
\hline factor1 & 0.16 & 26.8 & 2 & .000 & 0.55 & 0.56 & 0.51 \\
\hline
\end{tabular}

As the results in Table (10) show, the assumption of sphericity has not been met $(\mathrm{p}<0.05)$. Therefore, the epsilon values in Table (10) were used to adjust to the degrees of freedom of the F test and the results are shown in Table (11). 
TABLE (11):

TESTS OF WITHIN-SUBJECTS EFFECTS FOR TURKISH STUDENTS

\begin{tabular}{|ll|l|l|l|l|l|}
\hline Source & & $\begin{array}{l}\text { Type III Sum of } \\
\text { Squares }\end{array}$ & df & Mean Square & F \\
\hline \multirow{5}{*}{ factor1 } & Sphericity Assumed & 243.511 & 2 & 121.756 & 74.900 \\
& Greenhouse-Geisser & 243.511 & 1.1 & 226.517 & 74.900 \\
& Huynh-Feldt & 243.511 & 1.093 & 222.817 & 74.900 \\
& Lower-bound & 243.511 & 1.000 & 243.511 & 74.900 \\
& Sphericity Assumed & 45.822 & 28 & 1.637 & .000 \\
Error(factor1) & Greenhouse-Geisser & 45.822 & 15 & 3.045 & \\
& Huynh-Feldt & 45.822 & 15.300 & 2.995 & \\
& Lower-bound & 45.822 & 14.000 & 3.273 & \\
\end{tabular}

Mauchly's test indicated that the assumption of sphericity had been violated $\{x 2(2)=27, p<0.05\}$. Therefore, degree of freedom were corrected using Greenhouse-Geisser estimates $(\mathrm{e}=.54)$. The results show that there has been a significant effect of the sub-test taken $\{\mathrm{F}(1.1,15)=74.9, \mathrm{p}=.000\}$. The results also show that the participants have had different performances on the three different subtests. To find the sources of differences, we ran a-post hoc test the results of which are shown in Table (12).

TABLE (12):

PAIRWISE COMPARISONS

\begin{tabular}{|c|c|c|c|c|c|c|}
\hline \multirow[b]{2}{*}{ (I) factor 1} & \multirow[b]{2}{*}{ (J) factor 1} & \multirow[b]{2}{*}{ Mean Difference (I-J) } & \multirow[b]{2}{*}{ Std. Error } & \multirow[b]{2}{*}{ Sig. } & \multicolumn{2}{|c|}{ 95\% Confidence Interval for Difference } \\
\hline & & & & & Lower Bound & Upper Bound \\
\hline \multirow[t]{2}{*}{ Kurdish } & Arabic & 4.1 & .44 & .000 & 3.3 & 5.07 \\
\hline & Turkish & 4.3 & .35 & .000 & 3.7 & 5.2 \\
\hline Arabic & Turkish & 0.2 & .19 & .18 & -.14 & 0.66 \\
\hline
\end{tabular}

As the results in Table (12) show, there is a significant difference between the students' mean-on reading sub-test with Kurkish background and their means on the other two subtests( Arabic and Turkish), p=0.000, mean differences= 4.1 and 4.3. However, the results show that the difference between the Kurdish students' means on reading passages with Arabic and Turkish passages is not significant, $\mathrm{p}=0.18$ and mean difference is 0.2 .

\section{DISCUSSION}

This study was an attempt to investigate the relationship between cultural background of Iranian EFL learners and reading comprehension. In doing so, a test package containing three reading sub-tests (two culturally different tests, and one culturally specific test) was administered to three groups of language learners with three different cultural backgrounds living in the same country. The data of the study were analyzed through both descriptive and inferential statistics.

The finding of the present study was that ethnic language learners' mean scores on reading test with culturally specific contents were significantly different from their mean scores on reading tests containing culturally different contents (Tables 4, 8, 12). The results in Table (1) also showed that the groups' mean scores on reading tests containing culturally different contents were less than their means on reading tests with culturally specific items. The participants had the same performance on the reading tests containing different cultural issues. The finding is therefore consistent with the findings of many related studies (Droop \& Verhoeven, 1996; Bernhardt, 2005; Pulido, 2004; SalmaniNodoushan, 2003; Sharp, 2002; Peregoy \& Boyle, 2000; Bensoussan, 1998; Carrell 1984; Foo 1989; Goh 1990; Johnson, 1981, 1982). The main common finding of these researchers is that comprehension of receptive skills such as reading depends on knowledge; that is, linking what we don't know to what we already know.

So, one explanation is that background knowledge is important, and that content schema plays an integral role in reading comprehension.

The result is also consistent with Gilakjani and Ahmadi (2011) who have argued that the closer the consistency between the text and the reader's schema, the more comprehension occurs. Accordingly, it could be explained that comprehension of reading depends on specific knowledge which can link what we don't know to what we already know.

Furthermore, this finding is consistent with those of several researchers (e.g., Carrel \& Eisterhold, 1983; Williams, 1987; Cook, 1997, Harmer, 2001. Nunan, 2007) who have argued that when prior knowledge, which contradicts information in the text, is activated, readers may let prior knowledge override the text and that activation of background knowledge has several implications for teachers.

The results are also consistent with the findings of the studies by quite many researchers ( to name just a few, Carrell 1984; Foo 1989; Goh 1990; Bensoussan, 1998; Peregoy\& Boyle, 2000) who have argued that lack of an appropriate schema that can fit within the content of the text will result in the failure to make sense of a text. Therefore, it could be 
argued that the reading tests with unfamiliar contents, due to the lack of schema, could not help readers comprehend the passages easily.

Therefore, it could be argued that language learners living within the same country may not be familiar with the cultural backgrounds of the other minority groups and consequently may not be able to comprehend reading passages dealing with cultural issues different from theirs. This finding is consistent with that of Xiao (2001) who has argued that the rhetorical patterns of a text are language specific and culture-unique and reflect the thought pattern of a specific group.

\section{CONCLUSIONS}

In this study, the main focus was laid on the relationship between cultural background on reading comprehension by making a comparison between language learners' mean scores on reading sub-tests with culturally familiar contents, and culturally unfamiliar contents. On the basis of the findings, it can be concluded that:

a. Background knowledge is really instrumental in connecting the contextual meanings with EFL readers' comprehension.

b. The ability to understand a text is based not only on the reader's linguistic knowledge, but also on general knowledge of the world and the extent to which that knowledge is activated during processing.

c. With culturally relevant information, EFL students' prior and familiar experiences are valuable to their reading comprehension. As Floyd and Carrell (1987) suggested, the cultural-content -schema-training" (p.103) is a very powerful way to help readers' second language acquisition. In support of Floyd and Carrell's recommendation, localized literature may be used to activate learners' prior knowledge through reading about their familiar local cultures (Brock, 1990).

d. Conducting readers' cross-cultural background knowledge is absolutely a powerful instructional strategy to EFL reading comprehension.

e. If the unfamiliar content of a text has an effect on reading comprehension, then it must be considered as a criterion in the selection of reading materials and in the evaluation of reading comprehension.

f. Background knowledge (schemata) determines the ease or complexity of understanding the text. In other words, no matter how well a reader may know a language, he or she cannot read in that language with good comprehension if the subject matter or the content of the text is one he or she knows absolutely nothing about.

\section{IMPLICATIONS}

This study can have several implications for teachers, test designers, and language learners. EFL teachers should bear in mind that if the unfamiliar content of a text has an effect on reading comprehension, then it must be considered as a criterion in the selection of reading materials and in the evaluation of reading comprehension.

Third, as Greenberg (2006) has argued EFL teachers can use extensive reading (ER) to build up learners' background knowledge. Greenberg (2006) indicated that learners in extensive reading class should be encouraged to choose their reading materials by their own interests and proficiency levels. ER is a very learner-centered approach.

Fourth, teachers can design different types of reading activities and materials to increase their students' background knowledge.

Fifth, the syllabus designers should also provide the learners with culturally familiar reading passages in order to make teaching and learning atmospheres interesting.

Sixth, test designers and interpreter should know that any generalizations made about learners' general language proficiency on the basis of the test takers' performance on reading tests with familiar contents may not be fair and valid.

Finally, as reading the passages with familiar contents is easier than the other types of the reading passages, EFL learners are strongly recommended to make use of such passages in order to develop their reading skills.

\section{LIMITATIONS OF THE STUDY}

There are several limitations to the present study. The major limitation of the study was the sample size. In this study, the sample size is not large enough. With the small number of participants, the results of the study cannot be generalized to a large population. The third limitation of the study was sample selection. As it was very hard to select the participants randomly, the research had to select them through purposive sampling. Thus, the generalizations should be made with great care.

\section{RECOMMENDATIONS FOR FURTHER STUDIES}

This study has investigated the impact of cultural background on reading comprehension. This variable may influence language learners' performance on productive (encoding) skills. Therefore, the other researchers are recommended to study the impact of cultural background on EFL learners' writing and speaking.

In this study, the participants' major was the English language. The results may be different with students of other majors. Therefore, the other researchers are highly recommended to replicate this study with the other participants. 
Moreover, the other researchers are recommended to replicate the study using participants with different general language proficiency. They are also required to compare the effect of cultural background on language learners to see whether it has the same impacts on reading comprehension of EFL learners with general language proficiency.

\section{REFERENCES}

[1] Alderson, J. C. (2000). Assessing reading. Cambridge, England: Cambridge University Press.

[2] Alvermann, D. E., L. C. Smith, \& J. E. Readence. (1985). Prior knowledge activation and the comprehension of compatible and incompatible text. Reading Research Quarterly 20.3, 420-436.

[3] Anderson, R. C., \& P. D. Pearson. (1984). A schema-theoretic view of reading comprehension. In P. D. Pearson (Ed.), Handbook of Reading Research (pp. 255-291). New York: Longman.

[4] Ary, D., L. C. Jacobs, C. Sorenson \& A. Razavieh. (2008). Introduction to research in education (8th ed.). USA: Wadasworth Cenage Learning.

[5] Bensoussan, M. (1998). Schema Effects in EFL Reading Comprehension. Journal of Research in Reading 21, 213-227.

[6] Bernhardt, E. (2005). Progress \& procrastination in second language reading. In M. McGroarty (Ed.), Annual Review of Applied Linguistics 25, 133-150. New York: Cambridge University Press.

[7] Brock, M. N. (1990). The case for localized literature in the ESL classroom. English Teaching Forum 28.3, 22-25.

[8] Carrell, P. L. (1983). Some issues in studying the role of schemata, or background knowledge, in second language comprehension. Reading in a Foreign Language 1, 81-92.

[9] Carrell, P. L. (1984). Personality and individual writing processes. College Composition and Communications 35.2, 285-300.

[10] Carrell, P.L. (1987). Content and formal schemata in ESL reading. TESOL Quarterly 21.3, 461-481.

[11] Carrell, P.L. (1988a). Introduction: Interactive approaches to second language reading. In P. Carrell, J. Devine and D. Eskey. (Eds.), Interactive Approaches to Second Language Reading. Cambridge University Press: Cambridge.

[12] Carrell, P. L. \& J. C. Eisterhold. (1983). Schema Theory and ESL Reading Pedagogy. TESOL Quarterly 17.4, 553-573.

[13] Cook, G. (1997). Key Concepts in ELT: Schemas. ELT Journal 51.1, 86-86.

[14] Droop, M. \& L. Verhoeven. (1996). Linguistic and cultural diversity and reading comprehension development. In D. J. Leu, C. K. Kinzer, \& K. A. Hinchman (Eds.), Literacies for the 21st century: Research and practice. Forty-fifth yearbook of the National Reading Conference (pp. 317-328). Chicago: National Reading Conference.

[15] Floyd, P. \& P. L. Carrell. (1987). Effects on ESL reading of teaching cultural content schemata. Language Learning 37.1, 89105.

[16] Foo, R. W. K. (1989). "A Reading Experiment with L2 Readers of English in Hong Kong: Effects of the Rhetorical Structure of Expository Texts on Reading Comprehension," Hong Kong Papers in Linguistics and Language Teaching 12, 49-62.

[17] Goh, S. T. (1990). "The Effects of Rhetorical Organization on Expository Prose on ESL Readers in Singapore," RELC Journal 21.2, 1-11.

[18] Greenberg, D., V. Rodrigo, A. Berry, T. Brinck, \& H. Joseph. (2006). Implementation of an extensive reading program with adult learners. Adult Basic Education 16. 2, 81-97.

[19] Harmer, J. (2001). The Practice of English Language Teaching. Essex: Pearson Education Limited.

[20] Johnson, P. (1981). Effects of language complexity and cultural background of a text on reading comprehension. TEOSL Quarterly 15.2, 169-181.

[21] Johnson, P. (1982). Effects on Reading Comprehension of Building Background Knowledge. TESOL Quarterly 16.4, 503-516.

[22] Koh, M. Y. (1986). The role of prior knowledge in reading comprehension. Reading in a Foreign Language 3.4, $375-380$.

[23] Krashen, S. (1993). The power of reading: Insights from the research," Englewood, CO: Libraries Unlimited, Inc.

[24] Lipson, M. Y. (1983). The influence of religious affiliation on children's memory for text information. Reading Research Quarterly 18.4, 448-457.

[25] Nunan, D. (2007). What Is This Thing Called Language? London: Palgrave Macmillan.

[26] Peregoy, S. F. \& O. F. Boyle. (2000). English learners reading English: What we know, what we need to know. Theory Into Practice 39.4, 237-247.

[27] Pourhossein Gilakjani, A. \& S.M. Ahmadi. (2011). The relationship between L2 reading comprehension and schema theory: A matter of text familiarity. International Journal of Information and Education Technology 1.2, 142-149.

[28] Pulido, D. (2004). The relationship between text comprehension and second language incidental vocabulary acquisition: A matter of topic familiarity? Language Learning 54.3, 469-523.

[29] Salmani-Nodoushan, M. (2003). Text familiarity, reading tasks, and ESP performance: A study of Iranian LEP and non LEP university students. The Reading Matrix 3.1, 37-51.

[30] Sharp, A. (2002). "Chinese L1 Schoolchildren Reading in English: The Effects of Rhetorical Patterns," Reading in a Foreign Language 14.2, pp. 1-20.

[31] Singhal, M. (1998). A comparison of L1 and L2 reading: Cultural differences and schema. The Internet TESL Journal, 4 (10). http://iteslj.org/Articles/Singhal-ReadingL1L2.html (accessed 10/1/2012)

[32] Weber, R. (1991). Linguistic diversity and reading in American society. In R. Barr, M. L. Kamil, P. Mosenthal, \& P. D. Pearson (Eds.), Handbook of Reading Research (pp. 97- 119). New York: Longman.

[33] Williams, E. (1987). Classroom reading through activating content-based schemata. Reading in a Foreign Language, 4, 1-7.

[34] Xiao, L. (2001). English-Chinese Comparative Studies \& Translation, Shanghai Foreign Language Education Press, Shanghai. 


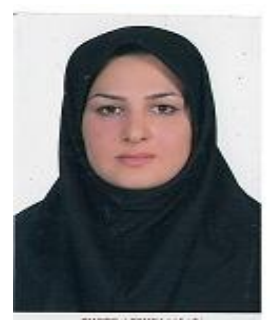

Hedieh Yousef was born in 1986 in Tehran, Iran. She completed her Bachelor Degree in French Translation in Allameh Tabatabai University, Tehran, Iran and further finished her Master Degree of Teaching English as a Foreign Language (TEFL) in Science \& Research University, Kermanshah, Iran.

Now she is working as an institutor and translator in language institutes. Her main areas of interest include TESOL, TEFL and translation.

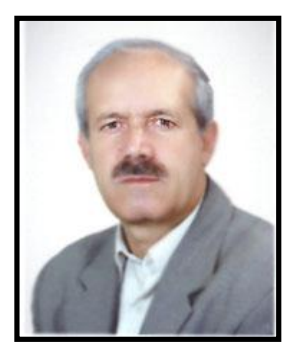

Lotfollah Karimi was born in 1962 in Sanandaj, Iran. He completed his Bachelor Degree in TEFL in Tabriz University, Tabriz, Iran, further finished his Master Degree of TEFL in Islamic Azad University, Tehran, Iran and got his PHD in TEFL in Islamic Azad University, Esfahan, Iran.

He is faculty member of Islamic Azad University of Hamadan, Iran and has been teaching courses in TEFL in B.A. and M.A. levels since 1990 up to now there.

His main areas of interest are research and applied linguistics. He has published several books like Fundamentals and Principles of Translation Theory and An Introduction to Morphology and articles in the field of TEFL and testing in different international journal such as World Applied Sciences Journal and Journal of Higher Education Studies.

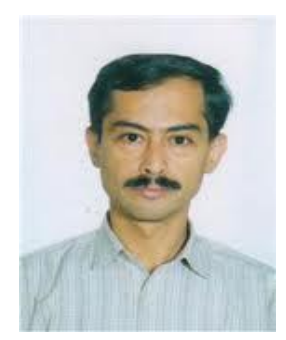

Kamran Janfeshan was born in 1966 in Kermanshah, Iran. He completed his B.A. in TEFL in Kordestan University, Sanandaj, Iran, obtained his M.A. in TEFL in University for teacher education, Tehran, Iran and further finished his PhD in TEFL in Pune University, India.

Now he is assistant professor of Applied Linguistics at Islamic Azad University, Kermanshah, Iran. His primary areas of interest include foreign language teaching, language learning and assessment. 